\title{
Application of ceramic dust as a modifier reducing the extent of rheological deformations in airfield pavement concrete
}

\author{
Matgorzata Linek ${ }^{1, *}$ \\ ${ }^{1}$ Kielce University of Technology, Faculty of Civil Engineering and Architecture, Department of \\ Transportation Engineering, Tysiąclecia Państwa Polskiego Street 7,25-314 Kielce, Poland
}

\begin{abstract}
The article presents material solution based on the application of ceramic dust as concrete mix component intended for airfield pavements. Material composition is intended for the application on the selected areas of pavement exposed to the influence of imposed thermal loads intensifying the stress strain state of concrete slabs. Due to the nature of loading of these parts it is necessary to reduce the extent of registered rheological deformations. Concrete containing dust additive is distinguished by more favourable porosity properties, more consistent cement matrix without visible discontinuities and with the formed different hydration products. Diversification of internal micro structure of cement concrete using the suggested dust has significant influence on the improvement of mechanical, physical and performance parameters. Also, assessment of the applied dust influence on the extent of the registered rheological deformations was presented. The analyses included concretes curing in standard conditions and concretes subject to thermal cycles representing the destructive influence of imposed loading. The obtained laboratory test results prove clearly the validity of the suggested solution. Reducing the extent of deformations is derivative of favourable changes observed in internal structure of concrete composite. Better formed contact areas provide the increased concrete parameters and consequently influence extending concrete durability.
\end{abstract}

\section{Purpose and scope of the research}

The purpose of the research was to define the influence of the applied ceramic dust on the change of parameters of hardened concrete exposed to the influence of the imposed thermal loads. Analyses included the determination of changes of extension of rheological deformations of concretes subjected to thermal cycles.

\section{Research materials}

\footnotetext{
*Corresponding author: linekm@tu.kielce.pl
} 
The extension of the observed shrinkage deformations is referred to reactivity and physical and mechanical properties of aggregate. Concerning the materials used for the research purposes, the shrinkage was determined during drying up thereof absorbability. Based on the obtained results, these materials were included in the alkaline non-reactive group. Properties of the applied aggregate (table 1) influence the opportunity of reducing the size of defects within contact area. Contact area is formed by cement matrix of thickness range of 10-50 $\mu \mathrm{m}$ within the vicinity of aggregate grain. Contact areas are distinguished by the increased porosity which enables faster penetration of water and aggressive substances. They are areas where potential damages of internal structure of concrete can occur.

Table 1. Properties of the applied aggregate.

\begin{tabular}{|c|c|c|c|}
\hline aggregate & granite grit & fine aggregate & ceramic dust \\
\hline shrinkage during drying [\%] & $<0.075$ & $<0.012$ & $<0.025$ \\
\hline absorbability [\%] & $<1.0$ & $<1.0$ & $<1.0$ \\
\hline alkaline reactivity & non-reactive & non-reactive & non-reactive \\
\hline
\end{tabular}

Due to the fact that selection of concrete mixture components has significant influence on the size of shrinkage deformation, coincident initial assumptions for mixtures CC-1 and CC-2 design were assumed. Aggregate composition is decisive in case of shrinkage size. The designed aggregate mixes (table 2) of series CC-1 and CC-2 complied with the requirements of [1] and were considered as good grain size distribution of airfield pavements. The experiment assumed to perform two series of concrete. The first series was reference concrete (CC-1), in accordance with the requirements of [1]. Series CC-2 included concrete with partial fine aggregate substitute in the form of ceramic dust $(0 / 2 \mathrm{~mm})$. Ceramic dust included crystalline components: quarc, mullite, cristobalite, corundum, very small amounts of clay minerals and anorthite.

Table 2. Material composition of mixes of series CC-1 and CC-2.

\begin{tabular}{|c|c|c|c|c|c|c|}
\hline \multirow{2}{*}{$\begin{array}{c}\text { Mixes of } \\
\text { series }\end{array}$} & \multirow{2}{*}{$\begin{array}{c}\text { Unit of } \\
\text { measurement }\end{array}$} & \multicolumn{3}{|c|}{ Granite grit } & Fine & Ceramic \\
\cline { 3 - 6 } & $16 / 32 \mathrm{~mm}$ & $8 / 16 \mathrm{~mm}$ & $2 / 8 \mathrm{~mm}$ & 670 & 415 & - \\
\hline $\mathrm{CC}-1$ & $\mathrm{~kg} / \mathrm{m}^{3}$ & 570 & 160 & 670 & 370 & 45 \\
\hline $\mathrm{CC}-2$ & $\mathrm{~kg} / \mathrm{m}^{3}$ & 570 & 160 & 670 dust \\
\hline
\end{tabular}

Mixes CC-1 and CC-2 included cement CEM I $42,5 \mathrm{~N}$ in the amount of $377 \mathrm{~kg} / \mathrm{m}^{3}$. Applied cement had reduced alkalis contents, its specific surface was $3431 \mathrm{~cm}^{2} / \mathrm{g}$. Admixtures in the form of air entrainment agent $\left(1.7 \mathrm{~kg} / \mathrm{m}^{3}\right)$ and plasticizing admixture $(0.7$ $\mathrm{kg} / \mathrm{m}^{3}$ ) were used in these mixes. Maximum value of $\mathrm{w} / \mathrm{c}$ ratio according to standard requirements [1] is $0.4 ; \mathrm{w} / \mathrm{c}$ ratio of the designed mixtures was assumed for 0.37 . The lower coefficient value of w/c can be assumed that lower volume of capillary pores, which resulted in decreasing shrinkage.

Laboratory tests assumed the diversified number of thermal test cycles. A single test cycle included process of alternate heating and cooling - fig. 1. Recurrent influence of temperature stimulated the impact of aircraft on airfield pavements. The assumed heating 
and cooling time corresponded to the time during which the aircraft effected the most frequently used airfield pavement within the area of Poland. Velocity of gas stream emitted during the test was $30 \mathrm{~m} / \mathrm{s}$.
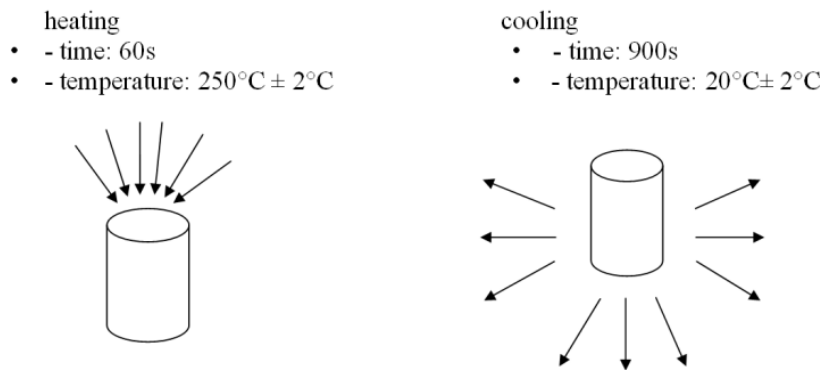

Fig. 1. Conditions assumed during the thermal research.

\section{Research methods}

During scientific research, the amount of the required samples was determined using student's T-distribution assuming the significance level of 0.05 . The minimum essential number of samples ranged between 4 and 5, depending on the type of the conducted test. In case of such assumptions, 6 samples were selected, which, each time, were intended for the laboratory tests. In case of concrete series A, D, E, H and K the extent of $\left(f_{c t}\right)$ tensile splitting strength was determined. The size of the test samples was $150 \times 300 \mathrm{~mm}$. Samples size and the loading method were consistent with the requirements of [1-3]. The samples were positioned centrically in the durometer which complied with the requirements of [4]. Along the bottom and upper edge of a sample, a pad was placed. These pads were made of fibreboard of density of $900 \mathrm{~kg} / \mathrm{m}^{3}$ and they were used for test purposes only once. Figure 2 presents the dimensions of the used pads. Load speed applied to the sample during the test was $0.05 \mathrm{MPa} / \mathrm{s}$. In the course of the test, maximum load value was determined. The concrete sample is capable to transfer the load before it is damaged.

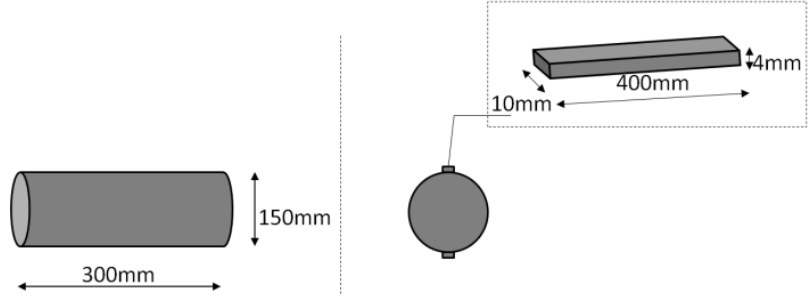

Fig. 2. Dimensions of samples and load diagram and dimensions of pads.

Concrete resistance $\left(f_{c t}\right)$ was determined according to formula (1) in which $F$ refers to maximum load applied to the sample $[\mathrm{N}], \mathrm{L}$ - refers to the contact length [mm], while $\mathrm{d}-$ refers to the cross section of the sample $[\mathrm{mm}]$.

$$
f_{c t}=2 \mathrm{~F} / \pi L d
$$

It was identified with concrete absorbability. In case of concretes of A series the ability of water absorption from the environment was determined. Samples of dimensions 150x150x $150 \mathrm{~mm}$ intended for absorbability testing cured in water of $20^{\circ} \mathrm{C}$ for the first 28 days, and then they were to determine absorbability $\left(\mathrm{n}_{\mathrm{w}}\right)$ in accordance with the guidelines 
of [1] according to (2); where $\mathrm{G}_{1}$ - dry sample weight (sample dried at temperature $105^{\circ} \mathrm{C}$ ), $\mathrm{G}_{2}$ - weight of water saturated sample.

$$
\mathrm{n}_{\mathrm{w}}=\left(\mathrm{G}_{2}-\mathrm{G}_{1}\right) / \mathrm{G}_{1} \cdot 100
$$

It was assumed that defining the influence of the applied dust on the change of extension of shrinkage deformations will take place in case of five series. Each time, 6 samples of concrete $\mathrm{CC}-1$ and $\mathrm{CC}-2$ stored in the same environmental conditions were subject to the analysis. The first (A) series, reference series, included CC-1 and CC-2 concrete curing for the period of 28 days completely immersed in water of temperature $20{ }^{\circ} \mathrm{C}$. Series D and $\mathrm{H}$ included CC-1 and CC-2 concrete stored from 28th day of curing in air-dry conditions. Series E and K included CC-1 and CC-2 concrete exposed to the influence of thermal cycles. The comparison of conditions during the test has been presented in Table 3.

Table 3. Test conditions for the research series (D, E, H and K).

\begin{tabular}{|c|c|c|c|c|c|}
\hline \multirow{2}{*}{ series } & Time & \multicolumn{2}{|c|}{ Temperature } & \multicolumn{2}{|c|}{ Humidity } \\
\hline & {$[\mathrm{s}]$} & \multicolumn{2}{|c|}{$\left[{ }^{\circ} \mathrm{C}\right]$} & \multicolumn{2}{|c|}{ [\%] } \\
\hline D & 96000 & \multicolumn{2}{|c|}{$20 \pm 2$} & \multicolumn{2}{|c|}{$46-64$} \\
\hline $\mathrm{E}$ & 96000 & $28 \pm 2$ & $20 \pm 2$ & $40-47$ & $56-65$ \\
\hline $\mathrm{H}$ & 192000 & \multicolumn{2}{|c|}{$20 \pm 2$} & \multicolumn{2}{|c|}{$44-60$} \\
\hline $\mathrm{K}$ & 192000 & $30 \pm 2$ & $20 \pm 2$ & $39-45$ & $56-64$ \\
\hline
\end{tabular}

In order to determine single shrinkage of CC-1 and CC-2 concrete lots $\mathrm{A}, \mathrm{D}, \mathrm{E}, \mathrm{H}$ and $\mathrm{K}$ six samples were used, in accordance with guidelines requirements [5], in the form of beams of cross section $150 \times 150 \times 600 \mathrm{~mm}$. Changes of sample length in the course of their drying were measured by means of measuring instrument of reading capacity of more than $0.005 \mathrm{~mm}$. Directly after removing each sample from a mould, locating distance do was determined. Socket extensometer and benchmarks stuck by means of quick-drying glue to the sample surface were used.

Assumed frequency of measurement series A performance included determination every 2 days for the period between the $1^{\text {st }}$ and the $10^{\text {th }}$ day, every 4 days for the period between the $7^{\text {th }}$ and $28^{\text {th }}$ day. Assumed frequency of measurement series D, E, H and K performance included determination every 2 days for the entire period.

Assumed research procedure complies with instruction [5]. In case of each analysed sample, after specified time, shrinkage deformation was determined $\varepsilon_{s}$, according to (3) formula, in which $d_{0}$ initial-basic distance (directly after unforming) between measuring points and $d_{t}$ is distance determined after anticipated drying time:

$$
\begin{gathered}
\varepsilon_{s}=\left(d_{0}-d_{t}\right) / d_{0} \\
\varepsilon_{\mathrm{cs}}=\varepsilon_{\mathrm{cd}}+\varepsilon_{\mathrm{ca}}
\end{gathered}
$$

The alternative method to specify shrinkage deformations of concrete CC-1 and CC-2 in A series included the determination of assumed deformation values in accordance with the guidelines of PN-EN 1992-1[6] and [7]. As the value of total shrinkage deformation $\left(\varepsilon_{\mathrm{cs}}\right)$ the total extent of autogenic shrinkage $\left(\varepsilon_{\mathrm{cd}}\right)$ and the shrinkage caused as a result of drying $\left(\varepsilon_{\mathrm{ca}}\right)$ was assumed, according to the formula (4). The value of the assumed shrinkage caused by drying was determined according to (5) in compliance with the assumptions of standard [6]. 


$$
\begin{gathered}
\varepsilon_{\mathrm{cd}(\mathrm{t})}=\beta_{\mathrm{ds}(\mathrm{t}, \mathrm{s})} \mathrm{k}_{\mathrm{h}} \varepsilon_{\mathrm{cd}, 0} \\
\varepsilon_{\mathrm{ca}(\mathrm{t})}=\beta_{\mathrm{as}}(\mathrm{t}) \varepsilon_{\mathrm{ca}}(\infty)
\end{gathered}
$$

The symbols in formula (5) coincide with symbols in [6], where: $t$ refers to concrete age in the considered moment; ts refers to at the beginning of drying /expansion process; $\beta_{\mathrm{ds}}$ was determined according to the formula 3.10 of standard [6]; $\mathrm{h}_{0}$ reliable cross section, $\mathrm{h}_{0}=$ 75; $\mathrm{u}$ refers to perimeter of part of section exposed to drying process and $\mathrm{k}_{\mathrm{h}}$ refers to the coefficient from the table 3.3 of standard [6] The value of autogenic shrinkage was determined according to (6) in compliance with the assumptions of standard [6]

Selected samples of CC-1 and CC-2 concrete subject to 100 and 200 thermal cycles were observed in scanning electron microscope. Samples preparation and interpretation of obtained results were in compliance with those described in subject literature [8]. Recent fracture were prepared from CC-1 and CC-2 concrete which were covered with carbon layer approx. 10nm thick. Preparation surface subject to observations by means of scanning electron microscope was not less than $1.0 \mathrm{~cm}^{2}$, and the scope of magnifying power was assumed between 200x to $100000 x$. During observations, special attention was paid to the structure of contact areas between aggregate grains and cement matrix, porosity characteristics and changes of cement matrix crystallization.

\section{Results and discussions}

Absorbability of concrete intended for airport pavements according to [1], which should not be higher than $5.0 \%$ for class $\mathrm{C} 30 / 37,4.9 \%$ for class $\mathrm{C} 35 / 45,4.9 \%$ for class $\mathrm{C} 40 / 50$ and $4.8 \%$ for class $\mathrm{C} 45 / 55$. According to the obtained laboratory tests results it was determined that concretes of series $\mathrm{CC}-1$ and $\mathrm{CC}-2$ complied with the requirements for the designed class $\mathrm{C} 40 / 50$. Moreover, CC-2 composed with the additive of dust is distinguished by the significantly lower absorbability. According to the analysis of the obtained test results of concrete series A it was proved that mechanical parameters of concretes CC-2 in all analysed cases are higher than parameters of concretes of CC-1. Significant influence (tab. 4) of the applied dust on the obtained tensile splitting strength. The applied dust is distinguished by the significant growth of tensile splitting strength after thermal cycles, which is associated with puzzolan properties. In a consequence of replacing cement with the suggested dust, the increase of average concrete tensile splitting strength in comparison to the reference concrete was proved. Increase in the strength was $31 \%$ after 200 thermal cycles. Reduction of concrete absorbability and increasing tensile splitting strength refers to the increased concrete durability.

Table 4. Determined parameters for $\mathrm{CC}-1$ and $\mathrm{CC}-2$ concrete.

\begin{tabular}{|c|c|c|c|c|c|c|}
\hline \multirow{2}{*}{ concrete } & \multicolumn{3}{|c|}{$\mathbf{N}[\%]$} & \multicolumn{3}{|c|}{$\mathbf{f}_{\text {ct }}[\mathrm{MPa}]$} \\
\hline & $\mathbf{X}$ & $\mathbf{S}_{\mathbf{d}}$ & $\mathbf{p}$-value & $\mathbf{X}$ & $\mathbf{S}_{\mathbf{d}}$ & $\mathbf{p}$-value \\
\hline $\mathrm{CC}-1$ & 3.98 & 0.08 & $<0.000001$ & 6.29 & 0.05 & $<0.000001$ \\
\hline $\mathrm{CC}-2$ & 3.19 & 0.03 & $<0.000001$ & 7.31 & 0.04 & $<0.000001$ \\
\hline $\mathrm{CC}^{100} 1^{100}$ & 4.41 & 0.06 & $<0.000001$ & 6.76 & 0.08 & $<0.000001$ \\
\hline $\mathrm{CC}^{100}$ & 3.32 & 0.04 & $<0.000001$ & 7.54 & 0.06 & $<0.000001$ \\
\hline $\mathrm{CC}^{200} 1^{200}$ & 4.89 & 0.07 & $<0.000001$ & 5.67 & 0.12 & $<0.000001$ \\
\hline $\mathrm{CC}^{200}$ & 3.53 & 0.04 & $<0.000001$ & 8.20 & 0.07 & $<0.000001$ \\
\hline
\end{tabular}


It was observed that in case of series A, the determined theoretical deformation of $\mathrm{CC}-1$ concrete proved diversification with respect to the values determined experimentally. The most significant differences were observed between the $10^{\text {th }}$ and the $28^{\text {th }}$ day of curing. Values of the determined deformations were lower than the values measured experimentally - Fig. 3a. Theoretical deformations determined after the assumed research period was $0.0271 \%$ while the one measured experimentally was $0.0420 \%$.

a)

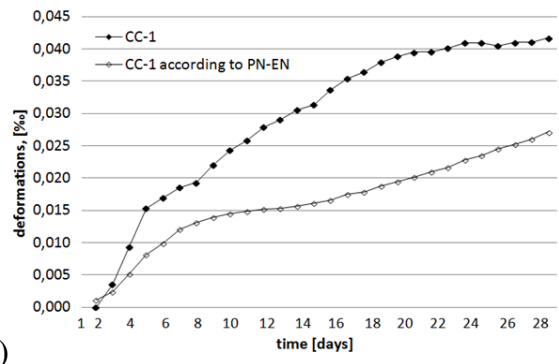

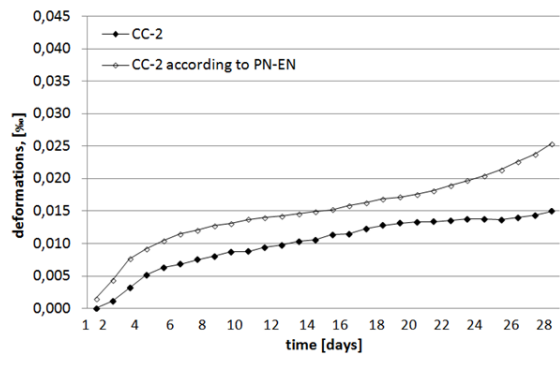

b)

Fig. 3. Deformations of concrete CC-1 (a) and CC-2 (b).

It was proved that in case of series A, the determined - theoretical deformations of CC2 concrete were more extensive than the deformations obtained as a result of laboratory tests - Fig 3b. The length of curing period influences the extent of the registered deformations. In case of laboratory tests, deformations stabilized after 20 days of curing. Application of ceramic dust reduces CC-2 concrete susceptibility to external factors. Changes of environment humidity to a lesser extent influence the range of the registered rheological deformations. Determined theoretical deformation after the assumed research period was $0.0254 \%$, while the one measured experimentally was $0.0149 \%$.

Table 5. Increasing shrinkage deformations of CC-1 and CC-2 concrete in various series (where: $\mathrm{T}$ indicates days, $\varepsilon_{\mathrm{p}}$ indicates initial deformation [\%o], and $\varepsilon_{\mathrm{k}}$ indicates final deformation [\%o]).

\begin{tabular}{|c|c|c|c|c|c|}
\hline \multirow{2}{*}{ series } & $\mathrm{t}$ & \multicolumn{2}{|c|}{ Concrete CC-1 } & \multicolumn{2}{c|}{ Concrete CC-2 } \\
\cline { 2 - 6 } & [days] & $\boldsymbol{\varepsilon}_{\mathbf{p}} \div \boldsymbol{\varepsilon}_{\mathbf{k}}$ & $\frac{\varepsilon_{k}-\varepsilon_{p}}{t}$ & $\boldsymbol{\varepsilon}_{\mathbf{p}} \div \boldsymbol{\varepsilon}_{\mathbf{k}}$ & $\frac{\varepsilon_{k}-\varepsilon_{p}}{t}$ \\
\hline $\mathrm{A}$ & 28 & $0.0012 \div 0.0417$ & $1.45 \times 10^{-3}$ & $0.0004 \div 0.0150$ & $5.21 \times 10^{-4}$ \\
\hline $\mathrm{D}$ & 26.6 & $0.0417 \div 0.0453$ & $1.35 \times 10^{-4}$ & $0.0150 \div 0.0169$ & $7.14 \times 10^{-5}$ \\
\hline $\mathrm{E}$ & 26.6 & $0.0417 \div 0.1547$ & $4.11 \times 10^{-3}$ & $0.0150 \div 0.0352$ & $7.59 \times 10^{-4}$ \\
\hline $\mathrm{H}$ & 53.2 & $0.0417 \div 0.0858$ & $8.29 \times 10^{-4}$ & $0.0150 \div 0.0190$ & $7.52 \times 10^{-5}$ \\
\hline $\mathrm{K}$ & 53.2 & $0.0417 \div 0.3951$ & $6.64 \times 10^{-3}$ & $0.0150 \div 0.0555$ & $7.61 \times 10^{-4}$ \\
\hline
\end{tabular}

According to the obtained results from the shrinkage deformations analysis it was proved that dust additive used in the composition of CC-2 concrete has significant impact on the extent of reduced shrinkage (Table 5). Regardless of environmental conditions and the time of thermal cycles influence, $\mathrm{CC}-2$ concrete is distinguished by reduced deformations. It was proven that $\mathrm{CC}-1^{\mathrm{A}}$ concrete cured for 28 days in water with a temperature of $20^{\circ} \mathrm{C}$ is distinguished by a deformation of $0.0417 \%$. In case of CC-2 $2^{\mathrm{A}}$ concrete this value was less than $0.0150 \%$ (Table $5-\mathrm{A}$ series). Deformations of CC- $1^{\mathrm{A}}$ concrete amount to $0.00145 \%$ and they are greater by order of magnitude than deformation 
of $\mathrm{CC}-2^{\mathrm{A}}$ concrete. It was proven that change in the curing conditions (series $\mathrm{D}, \mathrm{E}, \mathrm{H}$ and $\mathrm{K})$ also influences the phenomenon of increased shrinkage deformations. Samples of CC-1 and CC- 2 concrete stored for 100 and 200 cycles in air-dry conditions (average temperature $20{ }^{\circ} \mathrm{C}$ and the humidity range 44-64\%) are distinguished by average deformation lower than in case of thermal cycles. In each of these cases, deformations of CC-2 concrete are significantly lower than in case of CC- 1 concrete. Deformations of $\mathrm{CC}-1^{\mathrm{D}}$ concrete amount to $0.000135 \%$ and they are greater by order of magnitude than deformation of $\mathrm{CC}-2^{\mathrm{D}}$ concrete. Similar tendency is also observed after extending the period with subsequent 100 thermal cycles. The average deformation of $\mathrm{CC}-1^{\mathrm{H}}$ concrete is $0.000829 \%$, while in $\mathrm{CC}-2^{\mathrm{H}}$ concrete it is only $0.0000752 \%$. The favourable phenomenon is also the fact that with CC-2 concrete, the growth of deformations after 200 cycles is lower than after 100 cycles. It was proven that $\mathrm{CC}-2$ concrete exposed to thermal cycles ( $\mathrm{E}$ and $\mathrm{K}$ series) is distinguished by significantly less shrinkage deformations. It should be emphasized that deformations observed in case of CC-2 concrete, in each of the discussed cases (cycles from 1 to 200), reached significantly lower values than in case of CC- 1 concrete. Deformations of $\mathrm{CC}-1^{\mathrm{E}}$ concrete amount to $0.00411 \%$ and they are greater by order of magnitude than deformation of $\mathrm{CC}-2^{\mathrm{E}}$ concrete. Deformations of $\mathrm{CC}-2^{\mathrm{E}}$ concrete amount to $0.000759 \%$. Similar tendency is also observed after extending the period with subsequent 100 thermal cycles. The average deformation of $\mathrm{CC}-1^{\mathrm{K}}$ concrete is $0.00664 \%$, while in CC- $2^{\mathrm{K}}$ concrete it is only $0.000761 \%$. It is evidenced by the fact of the favourable influence of the applied dust on the reduction of deformations within a longer period of time.

The reasons for reducing deformations in CC- 2 concrete with regard to CC- 1 concrete should be found in favourable changes of internal structure of cement composite. According to SEM observations, it was determined that micro damages of cement matrix of concrete CC- $2^{100}$ and CC- $2^{200}$ series occur to a lesser extent in comparison to series CC- $1^{100}$ and $\mathrm{CC}-1^{200}$. Occasionally the occurring micro cracks of cement matrix of $\mathrm{CC}-2$ concrete are distinguished by widths not exceeding $6 \mu \mathrm{m}$ in case of concrete CC-2 $2^{100}$ and $8 \mu \mathrm{m}$ in case of concrete $\mathrm{CC}-2^{200}$. In case of these concretes, there are continuous contact areas between cement matrix and aggregate grains (Fig. 4b). This is particularly advantageous phenomenon, due to the fact that contact areas are distinguished by the increased porosity and in case of the occurrence of additional micro cracks contributing to the increased penetration of water or water and chemical substances, can clearly reduce the time of structure durability. Discontinuity of contact areas can be observed in concretes of series CC $-1^{100}$ and CC-1 $1^{200}$ - Fig. 4a. Micro cracks in these areas are up to $10 \mu \mathrm{m}$ in CC- $1^{100}$ concrete and up to $15 \mu \mathrm{m}$ in case of CC- $1^{200}$ concrete, accordingly. In case of cement matrix of $\mathrm{CC}-1^{100}$ concrete, micro cracks of the width of up to $14 \mu \mathrm{m}$ and in matrix of CC-1 $1^{200}$ concrete up to $18 \mu \mathrm{m}$ were observed. Observations by means of SEM proved that crystallization of ettryngite and fine-grained hydrated calcium silicate of $\mathrm{C}-\mathrm{S}-\mathrm{H}$ type prevails in cement matrix of CC- ${ }^{200}$ concrete. There are also fractured aggregate grains which contribute to weakening of internal structure of concrete and consequently to the reduction of its resistance to rheological deformations.
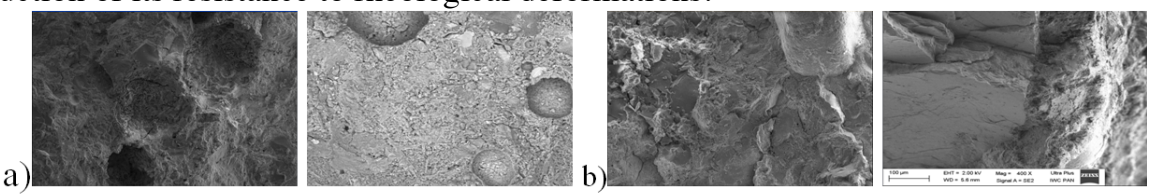

Fig. 4. Microstructure diversification (a) concrete CC-1 ${ }^{200}$ and (b) concrete CC-2 200 .

As a result of microstructure tests the influence of high temperature was proved which was generated on the surface of samples. Microstructure observations proved changes on the surface area. This was distinguished by the accumulation of carbonates in the amount 
strictly dependent on the assumed number of heating cycles. Within the surface area, increased porosity, with respect to layers located lower, was observed. During observations of CC-1 concrete series (Fig. 5a), numerous micro cracks were found, which were distinguished by significant widths and were not observed within surface layer of CC-2 concrete series (Fig. 5b). The phenomena observed in microstructure of concrete exposed to the influence of high temperature - series CC-2 (among others no micro cracks of surface area, continuous contact areas between cement matrix and aggregate grains and more favourable porosity characteristics) confirmed more favourable influence of modifier on parameters of hardened concrete. More favourably formed microstructure of CC-2 concrete series associated with better mechanical parameters (among others increased splitting resistance) and increased shrinkage deformations resistance proves the validity of using dust in the mix composition intended for airfield pavements.

a)

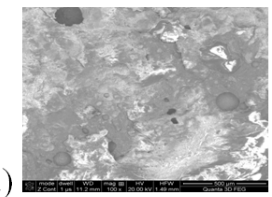

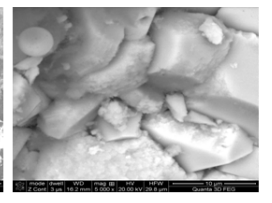

b)

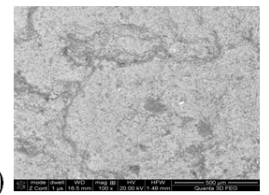

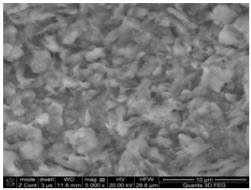

Fig. 5. The zone exposed to thermal cycles for concrete $\mathrm{CC}-1^{200}$ (a) and $\mathrm{CC}-2^{200}$ (b).

\section{Conclusions}

According to the conducted laboratory tests, the following conclusions have been reached:

- application of dust in the concrete mix composition has favourable influence on the reduction of the occurred micro damages of internal structure and porosity characteristics. The occurred hydration products and the size of individual crystals undergo change.

- the ceramic dust used in concrete mix contribute to the reduction of concrete absorbability by $0.79 \%$ after 28 days, $1.09 \%$ after 100 cycles and $1.36 \%$ after 200 thermal cycles.

- the ceramic dust used in concrete mix contribute to the increase of concrete tensile splitting strength after standard curing period by $14 \%$.

- the ceramic dust used in concrete mix contribute to increase of concrete resistance exposed to the influence of 100 and 200 thermal cycles accordingly by $10 \%$ and $31 \%$.

- the application of dust in the mix significantly influences the reduction of observed rheorogical deformations of hardened concrete by an order of magnitude.

\section{References}

1. NO 17-A204 (2015)

2. PN-EN 12390-2 (2011)

3. PN-EN 12390-6 (2011)

4. PN-EN 12390-4 (2011)

5. ITB Instruction No 194/98 (ITB, Warszawa, 1998)

6. PN-EN 1992-1-1 (2008)

7. W. Raczkiewicz, M. Bacharz, K. Bacharz, Adv. Mat. Sc. 15(2), 22-29 (2015)

8. M. Linek, IOP Conf. Series: Mat. Sc. Eng. 245, 032032 (2017) 